\title{
REVIEW \\ Vitamin D deficiency in individuals with a spinal cord injury: a literature review
}

\author{
JL Flueck and C Perret
}

Study design: Literature review of studies investigating vitamin D status in individuals with a spinal cord injury (SCI). Objectives: Prevalence of vitamin D deficiency seems to be high in the general population. Little is known regarding such a deficiency in individuals with a SCl. This review aimed to examine the literature that investigated vitamin D status in this population.

Setting: Switzerland.

Methods: A literature review was performed to investigate the prevalence of vitamin D deficiency in individuals with a SCI and to determine the factors leading to deficiency.

Results: Sixteen studies which met all the inclusion criteria were identified. All of these studies assessed total serum 25-hydroxy vitamin D status in individuals with an acute or chronic SCl. Overall, the prevalence of vitamin D deficiency or insufficiency seems to be high (range: 32-93\%) in this population compared with that in able-bodied persons. The main factors are immobility, low physical activity and bedrest, and therefore not enough exposure to sunlight. In addition, age, skin pigmentation, lesion level, occurrence of pressure ulcers, body mass index, season and latitude appeared to be further determinants for vitamin D deficiency. In athletes, playing their sport indoors or outdoors may have an additional role in developing vitamin D deficiency.

Conclusion: The available studies suggest that individuals with a SCl are at increased risk for vitamin D insufficiency/deficiency. Nutritional strategies and supplementation recommendations need to be developed to prevent these conditions in SCl.

Sponsorship: Not applicable.

Spinal Cord (2017) 55, 428-434; doi:10.1038/sc.2016.155; published online 8 November 2016

\section{INTRODUCTION}

An adequate vitamin $\mathrm{D}$ status has been shown to be important for the elderly, ${ }^{1,2}$ children ${ }^{3,4}$ and athletes. ${ }^{5}$ It has been suggested that a vitamin $\mathrm{D}$ deficiency might be related to a number of health issues such as rickets, ${ }^{6,7}$ osteoporosis, ${ }^{8}$ osteomalacia, ${ }^{9}$ cardiovascular diseases, ${ }^{10}$ hypertension, ${ }^{11}$ multiple sclerosis, Parkinson's and Alzheimer's disease ${ }^{12}$ and cancer. ${ }^{11,13}$ In addition, an insufficient vitamin $\mathrm{D}$ status might affect neuromuscular function ${ }^{14}$ that could lead to injuries and might also generate a higher risk for falls in the elderly. ${ }^{1}$ Individuals with a spinal cord injury (SCI) are-because of the complications of their impairment-per se already at a higher risk of osteoporosis or cardiovascular disease that are identified with a vitamin D deficiency and might lead to serious health problems. ${ }^{15}$ Osteoporosis, for example, is already widely spread among individuals with a SCI. ${ }^{16,17}$ Suffering from a concomitant vitamin D deficiency might worsen osteoporotic conditions. ${ }^{8,18}$ However, in hospitals and clinics, implementation of an adequate supplementation strategy prevents patients from such further health risks. In addition, there is no consensus what an ideal vitamin D supplementation strategy should comprise.

Besides an insufficient vitamin D supply from food, further common factors to develop a vitamin D deficiency involve insufficient exposure to sunlight, skin pigmentation and skin protection such as clothing or the use of sun blockers. ${ }^{19}$ In addition, season is one of the main factors in Northern latitudes leading to low vitamin D status due to the flat-angle of sunlight radiation during winter months that produces less vitamin $\mathrm{D}$ compared with an increase in the zenith angle resulting in more ultraviolet (UVB) radiation reaching the skin and a higher amount of vitamin $\mathrm{D}$ produced. ${ }^{20}$ These factors have to be taken into account when assessing vitamin $\mathrm{D}$ status in individuals with a SCI.

Exposure to sunlight is possibly very low or nonexistent in patients with a lesion-dependent low mobility or at bedrest. Moreover, these individuals keep their skin covered with clothing, as their skin is very sensitive because of less blood flow and thermoregulatory issues in the paralyzed extremities. If they are not cautious, they may develop a pressure ulcer causing further immobility or bedrest, leading to insufficient sun exposure. We therefore believe, vitamin D deficiency to be a very important topic for this population in hospitals and clinics. Furthermore, in athletes with a SCI, such a deficiency might possibly impair neuromuscular performance in addition and influence the rate of injuries. Therefore, our aim was to review all studies performed to investigate vitamin $\mathrm{D}$ status in spinal cord-injured individuals. Our main goal was to analyze the prevalence of vitamin D deficiency in a population with SCI to develop potential guidelines for inpatient settings. In addition, we aimed to detect the different factors leading to a vitamin D deficiency to prevent individuals with a SCI from such a deficiency.

\section{MATERIALS AND METHODS}

This literature review was undertaken by performing a literature search using Pubmed, Medline and Embase as search engines. Our 
analysis included only peer-reviewed articles published until June 2016 in English assessing 25-hydroxy vitamin D status. As inclusion criteria we defined a SCI or spina bifida, studies performed with humans and studies assessing vitamin D status in these individuals. Review articles, poster presentations, letters to the editor, position statements and studies performed with animals or including children were excluded from data analysis. In addition, studies assessing vitamin D status after a period of vitamin $\mathrm{D}_{3}$ supplementation were excluded. Nevertheless, if studies assessed vitamin D status as well as other parameters before a vitamin D supplementation period, baseline data of these studies were included. Studies performed assessing vitamin D status as a second outcome parameter with only minimal information on actual vitamin D status or prevalence of vitamin D deficiency were excluded from this review (for example, studies assessing bone health and measuring vitamin $\mathrm{D}$ status as a second outcome parameter). Only articles meeting all inclusion criteria were considered for the final analysis of the review process, whereas a first selection was undertaken based on a review of abstract contents and titles. The literature search was performed using the keywords outlined below combined as follows: ('vitamin D OR ergocalciferol OR 25-hydroxy vitamin D') AND ('SCI OR wheelchair athletes OR spina bifida'). The flow diagram of this literature search process is given in Figure 1.

\section{RESULTS}

Sixteen studies met all inclusion criteria for final analysis (Table 1). All these studies assessed vitamin D status (25-hydroxy vitamin D) in individuals with a SCI or a spina bifida. Most of these studies (14) were performed with individuals with a chronic SCI ( $>9$ months). Two studies investigated the vitamin D status in elite wheelchair athletes. ${ }^{21,22}$ Two studies investigated vitamin D status in individuals with an acute SCI ( $<9$ months). Most studies used $50 \mathrm{nmoll}^{-1}$ $\left(20 \mathrm{ng} \mathrm{ml}^{-1}\right)$ as the threshold for vitamin D deficiency and $75 \mathrm{nmoll}^{-1}\left(30 \mathrm{ng} \mathrm{ml}^{-1}\right)$ for suboptimal or insufficient vitamin D status. The use of different threshold values is stated in Table 1 for each study. Often, parathyroid hormone and plasma calcium concentrations were assessed supplementarily. Parathyroid hormone concentrations seemed to be higher than the normal level when individuals suffered from low vitamin D status. ${ }^{23,24}$ To further elucidate the relation of vitamin $\mathrm{D}$ and calcium concentration in bone health, the 16 articles were screened for this parameter as well.

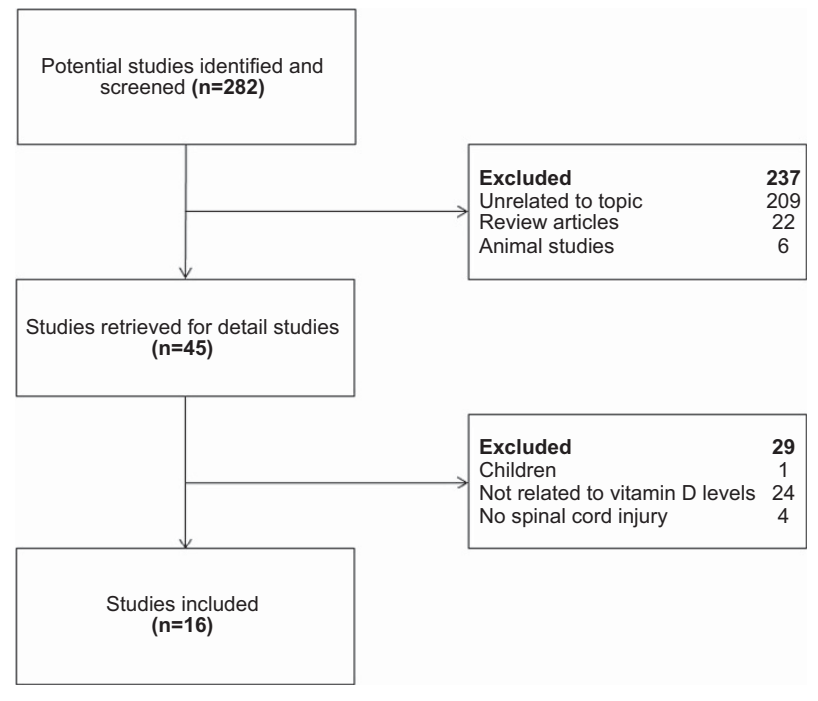

Figure 1 Study selection process.
Significantly lower calcium concentrations were found in patients with a SCI compared with that in able-bodied controls, ${ }^{25,26}$ whereas other researchers found no difference in calcium concentration between patients with a SCI and able-bodied controls. ${ }^{27,28}$ Comparing patients with a paraplegia to those with a tetraplegia, no significant difference was found in calcium concentration. ${ }^{26,29}$ Comparing calcium concentration in patients with a vitamin $\mathrm{D}$ deficiency to those without deficiency showed no significant difference. ${ }^{30,31}$ Furthermore, calcium concentration did not significantly increase, when vitamin D and calcium was administrated, ${ }^{24,32}$ although urinary calcium excretion significantly increased. ${ }^{32}$ Three studies ${ }^{30,31,33}$ assessed either functional ambulation category or leisure time physical activity and correlated these values with vitamin D status. Barbonetti, Sperandio ${ }^{30}$ found a correlation of low vitamin $\mathrm{D}$ status associated with high body mass index and poorer leisure time physical activity. Vitamin D status was strongly correlated with free and total testosterone levels in one study, ${ }^{31}$ whereas lower vitamin D status was associated with a lower free and total testosterone level in individuals with SCI.

Two studies ${ }^{24,32}$ investigated the influence of oral vitamin D supplementation (dose: $2000 \mathrm{IU} / 2 \times$ per week and $800 \mathrm{IU}$ per day) on vitamin $\mathrm{D}$ status. Both found significantly increased vitamin D status after supplementation and lower prevalence of vitamin $\mathrm{D}$ deficiency in these participants. In addition, parathyroid hormone concentration decreased significantly in these individuals. Two studies showed a higher prevalence of vitamin D deficiency during the winter months, ${ }^{21,34}$ whereas two other studies resulted in a lower vitamin D status in African Americans compared with that in Caucasians. ${ }^{34,35}$ A significantly lower vitamin D status was detected in patients compared with that in controls, ${ }^{26,28,33}$ whereas Vaziri, Pandian $^{25}$ did not find any difference between individuals with a SCI and able-bodied controls regarding vitamin D status. Zhou et al. ${ }^{26}$ discovered a higher amount of low vitamin D status in patients suffering from a pressure ulcer compared with that in patients without a pressure ulcer. Nemunaitis et al. ${ }^{35}$ found a significantly lower vitamin $\mathrm{D}$ status in patients with an incomplete injury compared with that in patients with a complete injury (14.6 vs $18.2 \mathrm{ng} \mathrm{ml}^{-1}$ ). Oleson et al. ${ }^{34}$ showed a higher amount of suboptimal or deficient vitamin D status in individuals with a chronic SCI compared with that in patients with an acute SCI. Finally, Hummel et al. ${ }^{23}$ related 'winter months', 'age', 'paraplegic', 'not on a vitamin D supplement', 'not on a calcium supplement' and 'not on a bisphosphonate therapy' to low vitamin $\mathrm{D}$ status.

\section{DISCUSSION}

This literature review showed that 16 studies met our inclusion criteria focused on vitamin D status in individuals with a SCI. Overall, a high occurrence of vitamin D deficiency in these individuals was found (range: 32-93\%). Vitamin D deficiency seems to be predominantly prevalent in individuals with a chronic ( $>9$ months after incident of injury) spinal cord lesion, whereas the deficiency was less pronounced for those with an acute spinal cord lesion $(<9$ months after incident of injury). Other factors seemed to involve functional independence, leisure time physical activity, skin pigmentation/ethnicity, latitude, season, existence of pressure ulcer and vitamin $\mathrm{D}$ or calcium supplementation.

\section{Vitamin D and parathyroid hormone status}

Significantly higher parathyroid hormone levels were found in patients with low vitamin D status compared with that in patients with normal vitamin D status. ${ }^{23,30}$ In total, $13 \%$ of these individuals ${ }^{23}$ suffered from hyperparathyroidism. However, these results might have been 
Table 1 Research literature investigating total serum 25-hydroxy vitamin D (25[OH]D) in individuals with a SCI

\begin{tabular}{|c|c|c|}
\hline Author & Participants & Methods \\
\hline $\begin{array}{l}\text { Pritchett } \\
\text { et al. } 22\end{array}$ & $N=39$ elite athletes with a $\mathrm{SCl}$ & $\begin{array}{l}\text { 25[OH]D measured in autumn and winter; } \\
\text { deficiency }<50 \mathrm{nmol} \mathrm{I}^{-1} \text {, insufficiency } \\
<80 \mathrm{nmol} \mathrm{I}^{-1}\end{array}$ \\
\hline $\begin{array}{l}\text { Flueck } \\
\text { et al. }{ }^{21}\end{array}$ & $\begin{array}{l}N=72 \text { elite wheelchair athletes ( } 164 \text { blood } \\
\text { samples) }\end{array}$ & $\begin{array}{l}25[\mathrm{OH}] \mathrm{D} \text { measured during the whole year; } \\
\text { insufficiency }<75 \mathrm{nmol} \mathrm{I}^{-1} \text {, deficiency } \\
<50 \mathrm{nmol} \mathrm{I}^{-1}\end{array}$ \\
\hline $\begin{array}{l}\text { Barbonetti } \\
\text { et al. } .^{30}\end{array}$ & $\begin{array}{l}N=100 \text { (72 men; } 28 \text { women) with chronic } \\
\mathrm{SCl} \text { admitted to rehabilitation program }\end{array}$ & $\begin{array}{l}\text { 25[OH]D, deficiency }<20 \mathrm{ng} \mathrm{ml}^{-1} \\
\left(=50 \mathrm{nmol} \mathrm{I}^{-1}\right), \text { LTPA, ADL }\end{array}$ \\
\hline $\begin{array}{l}\text { Benlidayi } \\
\text { et al. }\end{array}$ & $\begin{array}{l}N=173 \text { (118 patients; } 55 \text { controls) patients } \\
\text { with SCl and hemiplegia }\end{array}$ & $\begin{array}{l}25[\mathrm{OH}] \mathrm{D} \text {, effect of } \mathrm{FAC} \text {, lesion level and Brunn- } \\
\text { strom's recovery stage on vitamin } \mathrm{D} \text { status }\end{array}$ \\
\hline
\end{tabular}
strom's recovery stage on vitamin D status

$\begin{array}{ll}\text { Barbonetti } & N=49 \text { men with chronic SCI, rehabilitation } \\ \text { et al. }{ }^{31} & \text { program }\end{array}$

Javidan et al. ${ }^{29} \quad N=160$ patients with chronic SCl

Hummel

et $a .^{23}$

Bauman

et al. ${ }^{24}$

Oleson et al. ${ }^{34}$

$N=96$ patients with motor complete $\mathrm{SCl}$,

acute and chronic injury a chronic $\mathrm{SCl}, 86 \%$ taking vitamin D supplementation

$N=7$ individuals with a chronic SCl

mainly acute SCI
25[OH]D, suboptimal $<30 \mathrm{ng} \mathrm{ml}^{-1}$ (75 nmol ${ }^{-1}$ ), deficient $<20 \mathrm{ng} \mathrm{ml}^{-1}$ $\left(50 \mathrm{nmol} \mathrm{I}^{-1}\right)$, Serum testosterone levels, LTPA

25[OH]D, insufficiency $<20 \mathrm{ng} \mathrm{ml}^{-1}$ $\left(50 \mathrm{nmol} \mathrm{I}^{-1}\right)$, deficiency $<13 \mathrm{ng} \mathrm{ml}^{-1}$ (32.5 nmol I-1), food questionnaire, calcium $25[\mathrm{OH}] \mathrm{D},<75 \mathrm{nmol} \mathrm{I}^{-1}$ suboptimal status, PTH, calcium

25[OH]D, deficient $<20 \mathrm{ng} \mathrm{ml}^{-1}$ $\left(<50 \mathrm{nmol} \mathrm{I}^{-1}\right)$, relatively deficient 20-30 $\mathrm{ng} \mathrm{ml}^{-1}\left(<75 \mathrm{nmol} \mathrm{I}^{-1}\right)$, not deficient $>30 \mathrm{ng} \mathrm{ml}^{-1}\left(>75 \mathrm{nmol} \mathrm{I}^{-1}\right)$, iPTH, oral vitamin $D_{3}$ supplementation (2000 IU daily) prescribed for 90 days

25[OH]D, deficiency $<13 \mathrm{ng} \mathrm{ml}^{-1}$ $\left(<30 \mathrm{nmol} \mathrm{I}^{-1}\right)$, insufficiency $<20 \mathrm{ng} \mathrm{ml}^{-1}$ $\left(<50 \mathrm{nmol} \mathrm{I}^{-1}\right)$, subtherapeutic $<32 \mathrm{ng} \mathrm{ml}^{-1}$ $\left(<77 \mathrm{nmol} \mathrm{I}^{-1}\right)$, calcium and PTH

$25[\mathrm{OH}] \mathrm{D}$, severe deficiency $<10 \mathrm{ng} \mathrm{ml}^{-1}$ $\left(<25 \mathrm{nmol} \mathrm{I}^{-1}\right)$, inadequate $<30 \mathrm{ng} \mathrm{ml}^{-1}$ $\left(<50 \mathrm{nmol} \mathrm{I}^{-1}\right)$, adequate $>30 \mathrm{ng} \mathrm{ml}^{-1}$ $\left(>75 \mathrm{nmol} \mathrm{I}^{-1}\right)$
Results

$15.4 \%$ of all samples deficient and $51.3 \%$ insufficient during autumn; $15.4 \%$ of all samples deficient and $41 \%$ insufficient during winter; no significant difference between indoor and outdoor sports

$73.2 \%$ of all samples insufficient or deficient, significantly higher status during summer compared with that in winter; higher amount of insufficiency or deficiency in indoor $(80.9 \%)$ compared with that in outdoor athletes (70.1\%)

$78 \%$ of all samples deficient, $72 \%$ of all men and $93 \%$ of all women, samples with low vitamin D status were associated with higher BMI, lower ADL and poorer weekly LTPA; low vitamin D predictor for poor physical function

Vitamin D significantly lower in patients compared with that in controls; vitamin D insufficiency higher in non-functionally ambulatory compared with that in functionally ambulatory patients; no significant differences in vitamin D by lesion level and Brunnstrom's score

$73.5 \%$ of all samples deficient; $22.4 \%$ of all samples suboptimal status and only $4.1 \%$ (2 men) sufficient vitamin D status; significant correlation between vitamin $D$ and total and free testosterone

Average vitamin D was $13.6 \pm 11.0 \mathrm{ng} \mathrm{ml}^{-1} ; 53.1 \%$ of all samples vitamin $D$ deficient, vitamin $D$ intake below recommendations

$39 \%$ suboptimal status, $10 \%$ below $50 \mathrm{nmol} \mathrm{I}^{-1}, 6 \%$ suboptimal vitamin D and high PTH, 87\% normal PTH status, winter months associated with low vitamin D; 'paraplegic', 'not on a vitamin D supplement', 'not on a calcium supplement' and 'not on bisphosphonate therapy' predictor for vitamin D deficiency

At baseline all participants were vitamin $D$ deficient $\left(14 \pm 2 \mathrm{ng} \mathrm{ml}^{-1}\right)$, after 1 month of supplementation of vitamin $D$ increased to $26 \pm 6 \mathrm{ng} \mathrm{ml}^{-1}$, after 3 months vitamin $\mathrm{D}$ level increased to $48 \pm 17 \mathrm{ng} \mathrm{ml}^{-1}$, only one individual failed to reach normal vitamin $D$ level (baseline value of

$17 \mathrm{ng} \mathrm{ml}^{-1}$ ), iPTH significantly decreased at months 1 and 3 compared with that in baseline Summer: $65 \%$ patients with acute and $81 \%$ patients with chronic $\mathrm{SCl}$ subtherapeutic vitamin D status, winter: $84 \%$ of patients with acute and $96 \%$ of patients with chronic $\mathrm{SCl}$ subtherapeutic vitamin D status, lower vitamin D status in African Americans relative to Caucasians, significant main effects for season, chronicity and ethnicity $93 \%$ of all samples inadequate or severe deficient, mean vitamin D status was $16.3 \pm 7.7 \mathrm{ng} \mathrm{ml}^{-1}, 21 \%$ of all samples severely deficient, significantly lower vitamin D status in African American patients compared with that in Caucasian, patients with incomplete injury had significantly lower vitamin D status compared with those who had complete $\mathrm{i}$ njuries (14.6 vs $18.2 \mathrm{ng} \mathrm{ml}^{-1}$ ), no difference between summer and winter months 
Table 1 (Continued)

\begin{tabular}{|c|c|c|}
\hline Author & Participants & Methods \\
\hline $\begin{array}{l}\text { Bauman } \\
\text { et al. } 32\end{array}$ & $\begin{array}{l}\text { Study 1: } N=10 \text { individuals with chronic } \mathrm{SCl} \text {; } \\
\text { study 2: } N=40 \text { individuals with chronic SCl}\end{array}$ & $\begin{array}{l}25[\mathrm{OH}] \mathrm{D} \text {, study } 1 \text { : twice a week } 50 \mu \mathrm{g}(2000 \mathrm{IU}) \\
25 \text {-hydroxy vitamin } \mathrm{D}_{3} \text { supplementation for } \\
14 \text { days; study } 2 \text { : daily } 800 \mathrm{IU}(20 \mu \mathrm{g}) \text { vitamin } \\
\mathrm{D}_{3} \text { supplementation for } 12 \text { months }\end{array}$ \\
\hline
\end{tabular}

$\begin{array}{lll}\text { Pedrera } & N=35 \text { male individuals with a chronic para- } & 25[\mathrm{OH}] \mathrm{D} \text { and PTH measured in January and } \\ \text { et al. } & \text { plegia, } N=35 \text { able-bodied controls } & \text { February }\end{array}$

Mechanik

et al. ${ }^{37}$

$N=33$ controls (traumatic brain injury),

$N=14$ complete tetraplegia, $N=15$

incomplete tetraplegia, $N=15$ complete

paraplegia, $N=5$ incomplete paraplegia

Bauman

et al. $^{27}$

$N=100$ individuals with chronic SCl (49 with $25[\mathrm{OH}] \mathrm{D}, \mathrm{PTH}$

paraplegia, 51 with tetraplegia), $N=50$

matched able-bodied controls

25[OH]D, PTH
Results

Study 1: vitamin D increased significantly in 14 days

from 8.7 to $14.7 \mathrm{ng} \mathrm{ml}^{-1}$; 8 of 10 individuals still

below normal vitamin D status, PTH decreased

significantly, study 2: after 12 months of supplementation, 9 individuals absolute and 23 relative vitamin D deficiency compared with 33 and 6 individuals, respectively, at baseline, vitamin D increased significantly from 10.7 to $22.5 \mathrm{ng} \mathrm{ml}^{-1}$ and PTH decreased significantly

Significantly lower vitamin D status in paraplegic patients compared with that in controls (20 $\mathrm{ng} \mathrm{ml}^{-1}$ vs $32 \mathrm{ng} \mathrm{ml}^{-1}$ ), higher PTH levels in paraplegic patients compared with that in controls, $46 \%$ vitamin D status below $15 \mathrm{ng} \mathrm{ml}^{-1}$ defined as vitamin D deficiency, $20 \%$ of the patients PTH above the upper limit of the norm values, significant negative association between the duration of the injury and vitamin D status

Patients with $\mathrm{SCl}$ significant suppression of PTH, mean vitamin D concentrations normal among all groups with abnormal low levels found in 34\% of patients with $\mathrm{SCl}$ and $25 \%$ of patients with brain injury,

$32 \%$ of $\mathrm{SCl}$ patients and $16 \%$ of controls were deficient, mean value of these deficient samples were significantly lower in $\mathrm{SCl}$ compared with those in control ( 8 vs $14 \mathrm{ng} \mathrm{ml}^{-1}$ ), 11 individuals with elevated PTH and elevated 1,25-D, negative correlation between PTH and vitamin D in SCl, samples with high PTH showed significantly lower vitamin D levels compared with samples with low PTH (10 vs $29 \mathrm{ng} \mathrm{ml}^{-1}$ )

No significant difference of vitamin $\mathrm{D}$ between $\mathrm{SCl}$ and control, serum calcitriol concentration significantly lower in $\mathrm{SCl}$ compared with that in control, PTH positively correlated with 1, 25-vitamin D Significantly lower vitamin D in $\mathrm{SCl}$ compared with that in controls, significantly lower vitamin $\mathrm{D}$ in $\mathrm{SCl}$ with pressure ulcer compared with that in $\mathrm{SCl}$ without pressure ulcer.

Abbreviations: ADL, functional independence in activities of daily living; BMI, body mass index; FAC, Functional Ambulation Category; iPTH, intact parathyroid hormone; LTPA, leisure time physical Abbreviations: ADL, functional independence in activities of daily living; BMI, body mass index; F,
activity; PTH, parathyroid hormone; SCI, spinal cord injury; 1,25-D, 1,25-dihydroxy vitamin D.

influenced by the fact that parathyroid hormone concentrations increase gradually from $0,6,12$ to 36 months after the incidence of a SCI. ${ }^{36}$ Furthermore, Bauman et al. ${ }^{24}$ showed that after vitamin D supplementation of $800 \mathrm{IU}$ per day, total serum vitamin D increased and parathyroid hormone concentrations decreased. After 3 months of vitamin D supplementation almost all of their participants reached normal vitamin D status $\left(>30 \mathrm{ng} \mathrm{ml}^{-1}\right)$. Also Pedrera et al. ${ }^{28}$ found a negative association between vitamin $\mathrm{D}$ status and parathyroid hormone concentration as well as between vitamin D status and injury duration. Parathyroid hormone concentration was significantly higher in traumatic brain-injured patients compared with that in individuals with complete or incomplete tetraplegia. ${ }^{37}$ However, mean $25[\mathrm{OH}]$ vitamin $\mathrm{D}$ concentrations were normal among all different groups in this study with $34 \%$ of patients with a SCI showing abnormal low concentrations. The association between parathyroid hormone and vitamin $\mathrm{D}$ is explained by the fact that vitamin $\mathrm{D}$ suppresses genetic transcription of parathyroid hormones. ${ }^{38}$ Therefore, less vitamin D would suppress the production of parathyroid hormones to a lesser extent, which would increase parathyroid hormone concentration. A recent meta-analysis ${ }^{39}$ showed a significant decrease in parathyroid hormone levels after vitamin D supplementation in healthy individuals with a vitamin D deficiency. Another cohort study with an older Dutch population ${ }^{40}$ clearly showed the association of low vitamin D status in the presence of high parathyroid hormone concentrations. These authors concluded that it is very important to establish reference values for the parathyroid hormone concentration taking the vitamin D status into account. As this association between these vitamin $\mathrm{D}$ and parathyroid hormone concentrations does not differ in spinal cordinjured individuals, it is also important to further investigate the influence of parathyroid hormone supplementation in this special population. 


\section{Vitamin D and calcium status}

It is well recognized that ionized calcium significantly increases in the early stage of a SCI, whereas serum calcium concentration remains normal. ${ }^{41}$ In patients with a chronic SCI, serum calcium concentration significantly decreases. ${ }^{41}$ Comparing calcium concentrations found in patients with a SCI with that in able-bodied controls, results are equivocal. ${ }^{25-28}$ It seems that calcium concentration is not influenced by the lesion level (for example, para- or tetraplegia). ${ }^{26,29}$ In addition, no link between calcium concentration and vitamin D deficiency is found in patients with a SCI. ${ }^{30,31}$ This is supported by the results of two studies, ${ }^{24,32}$ which showed no significant increase in calcium concentration when vitamin $\mathrm{D}$ and calcium were concomitantly administrated. The interaction of vitamin D and calcium concentration needs to be elucidated in future studies in order to develop an accurate supplementation strategy.

\section{Vitamin D and testosterone status}

A recent review investigated the association of vitamin $\mathrm{D}$ and reproduction, ${ }^{42}$ and vitamin $\mathrm{D}$ seems to be involved in many different functions associated with reproduction. Vitamin D receptors are present in the reproductive system of both, men and women. However, vitamin D might indirectly influence testosterone status by regulating production and secretion of osteocalcin in bone. ${ }^{43}$ Osteocalcin binding on receptors in testes seems to influence testosterone production in males but not in females. ${ }^{44}$ Therefore, it is not surprising, that significantly lower free and total testosterone levels and higher parathyroid hormone concentrations ${ }^{30}$ are found in men with a SCI suffering from a vitamin D deficiency. A strong correlation between free testosterone and vitamin D status and an androgen deficiency was observed in almost $35 \%$ of all samples. Only one of these individuals showed a normal vitamin D status with all others being vitamin D deficient. This study was the only one investigating the relationship of vitamin $\mathrm{D}$ and testosterone levels in individuals with a SCI. In healthy, able-bodied men, vitamin D status was correlated with testosterone concentrations at baseline measurements as well. ${ }^{45}$ In that study, participants were supplemented with vitamin D up to 16 weeks with different dosages (range: 600-2000 IU per day). Vitamin D status significantly increased whereas testosterone levels did not differ after the supplementation period. Another randomized placebo-controlled study ${ }^{46}$ showed a significant increase in free and total testosterone levels following vitamin D supplementation (over 3000 IU per day) in overweight men over a duration of one year. Further research is needed to clarify the role of vitamin D supplementation on testosterone status in individuals with a SCI.

\section{Vitamin D and pressure ulcers}

A correlation between the occurrence of pressure ulcer and the vitamin $\mathrm{D}$ status in individuals with a para- or tetraplegia has been reported. ${ }^{26}$ Individuals with a para- or tetraplegia without suffering from pressure ulcers show a significantly higher vitamin D status compared with individuals suffering from a pressure ulcer. As these data were collected from hospitalized patients; it is unknown whether the low vitamin D status occurred because of the inability to freely move outdoors in patients suffering from pressure ulcers. We assume that the patients without pressure ulcers were able to move outdoors and get enough sunlight exposure to produce a sufficient amount of vitamin D. Another study investigated the association of vitamin D and pressure ulcer in an elderly study population. ${ }^{47}$ In this study, vitamin $\mathrm{D}$ deficiency was associated with pressure ulcers with an odds ratio of 1.871 and a $P$-value of 0.015 , but the occurrence of comorbidities was also associated with a vitamin $\mathrm{D}$ deficiency. In a final regression model after adjusting for comorbidities, the association between vitamin D deficiency and pressure ulcers became nonsignificant. As vitamin D receptors are present in keratinocytes, sebocytes as well as in dermal papilla and vitamin D is related to proliferation, differentiation and immunoregulation, one can speculate that vitamin $\mathrm{D}$ might have an important role in skin health. ${ }^{47}$ Therefore, further research has to be conducted to clearly link vitamin $\mathrm{D}$ deficiency with pressure ulcers to show potential benefits of vitamin D supplementation on wound healing in patients with pressure ulcers.

\section{Predictors for vitamin D deficiency in individuals with a SCI}

Several studies in this review showed the occurrence of potential predictors for vitamin $\mathrm{D}$ deficiency. In that context, some studies revealed that ethnicity might be one of these predictors. Oleson et al. ${ }^{34}$ showed lower vitamin D status in African Americans compared with that in Caucasians. The same findings were described by Nemunaitis et al. ${ }^{35}$ again with significantly lower vitamin D status in African Americans compared with that in Caucasians. The same outcome was found in able-bodied individuals where the authors investigated the influence of UVB radiation on vitamin D status. ${ }^{48}$ These results showed that only fair-skinned individuals were able to significantly increase their vitamin D status after 6 days of UVB radiation compared with black skinned individuals. Several studies from this literature review found a lower vitamin D status or a higher amount of insufficient or deficient vitamin $\mathrm{D}$ samples during the winter months $s^{21,23,34}$ in individuals with a SCI. Two of these studies were performed in the Northern latitude (Canada and Switzerland) that is known to influence vitamin D status especially during the winter months, where a flat-angle sunlight radiation prevents a sufficient vitamin D production. In addition, in these countries daily hours of sunlight are much lower during the winter months compared with those in summer months. Furthermore, a high body mass index was found to be correlated to a low vitamin D status in individuals with a SCI. ${ }^{30}$ These findings might be explained by a possible retention of vitamin D metabolites by an excess of body fat. Further, cholecalciferol produced by the skin might be sequestered by the body fat. Therefore, bioavailability of vitamin $\mathrm{D}$ decreases in obesity. ${ }^{49}$ Lower functional independence as well as poorer weekly leisure time physical activity have been correlated as well to a poor vitamin $\mathrm{D}$ status in individuals with a SCI. ${ }^{30}$ Similar results were shown by Benlidayi et al. ${ }^{33}$ whereas a higher amount of vitamin D insufficiency was found in nonfunctionally ambulatory individuals with a SCI compared with functionally ambulatory patients. Hummel et al. ${ }^{23}$ showed that being an individual with a paraplegia is associated with a vitamin D deficiency compared with individuals with a tetraplegia. Flueck et al..$^{21}$ detected significantly lower vitamin $\mathrm{D}$ status in individuals with a tetraplegia compared with individuals with a paraplegia during the winter months. Another study ${ }^{35}$ did not find any significant difference in vitamin $\mathrm{D}$ status between individuals with paraplegia and tetraplegia, although individuals with an incomplete spinal cord lesion showed a significant lower vitamin D status compared with individuals with a complete lesion. Similar results were found in another study with no difference in vitamin $\mathrm{D}$ status comparing individuals with paraplegia and tetraplegia to able-bodied controls. ${ }^{25}$ In contrast, Zhou et al. ${ }^{26}$ reported a significantly lower vitamin D status in individuals with a tetraplegia compared with individuals with a paraplegia. These results showed clearly, that having a SCI may produce a high variability in functionality, mobility as well as independence. Besides the level and the completeness of the lesion, functionality, mobility as 
well as independence need to be assessed as well to detect an association between the severity of the impairment and the vitamin $\mathrm{D}$ status. Therefore, it seems not obvious whether having a paraplegic or a tetraplegic lesion might be a better predictor for lower vitamin D status. Moreover, the impact of functionality seems to have a higher impact on vitamin $\mathrm{D}$ deficiency in this population as patients restrained to bedrest or in constant need of assistance will not spend enough time in the sun. Thus, an assessment of functionality such as leisure time physical activity or the extent of remaining ambulatory function need to be included in future studies.

Oleson et al. ${ }^{34}$ compared individuals with an acute and chronic traumatic SCI. They found a higher amount of vitamin D deficient samples in individuals with chronic lesions compared with that in individuals with an acute SCI. It is worth noting that, both groups showed a very high prevalence of vitamin D deficiency (65-96\%). As only one study compared these two groups of patients, further prospective studies are needed to investigate the alteration of vitamin D status following the incidence of a traumatic SCI in the long term.

\section{Vitamin D in wheelchair athletes}

Two studies investigated the vitamin $\mathrm{D}$ status in wheelchair athletes. ${ }^{21,22}$ Flueck et al. ${ }^{21}$ found a higher occurrence of vitamin D deficiency or insufficiency in indoor compared with outdoor athletes. Overall, a very high occurrence of vitamin D insufficiency or deficiency was found in $73 \%$ of all samples. In the other study 15.4 and $51.3 \%$ of all autumn samples were considered to be deficient and insufficient, respectively. During winter, very similar results were shown with $15.4 \%$ vitamin D deficient and $41 \%$ insufficient samples. This study included a high variation of geographical locations of the individuals that could have influenced the study outcome. In some regions there might be enough sunlight radiation to produce vitamin $\mathrm{D}$ during the winter months in the US. Compared with studies performed with able-bodied athletes, the prevalence of vitamin D insufficiency seems to be high in wheelchair athletes. UK athletes showed a prevalence of $57 \%$ deficient vitamin D samples, ${ }^{50}$ whereas US athletes showed a prevalence of $12-42 \%$ of insufficient vitamin D samples. ${ }^{51-53}$ Only able-bodied Israeli indoor athletes showed a high amount of insufficient vitamin D status with an occurrence of $73 \%{ }^{54}$ In a recent meta-analysis ${ }^{5}$ it was shown that the risk for a vitamin $\mathrm{D}$ deficiency increased for athletes training indoors as well as during the winter months. The association of injuries in athletes with a deficient vitamin $\mathrm{D}$ status as well as impaired performance under vitamin D deficiency is not yet fully understood. Further studies are needed to draw any conclusions and to develop further guidelines on how to supplement the athletes.

\section{Limitations}

Unfortunately, it was not possible to adjust the study outcomes to the same threshold as for vitamin D deficiency or insufficiency. Not enough data were provided to calculate the prevalence of vitamin D deficiency in a study with a lower threshold for deficiency (for example, $30 \mathrm{nmoll}^{-1}$ ) to the commonly used threshold of $50 \mathrm{nmoll}^{-1}$. The lack of a guideline for this threshold values is not the only limitation of this review. In addition, not all studies used the same method to assess vitamin D status. Some of them used chemiluminescent immunoassays, ${ }^{23,30,33}$ others radioimmunoassays, ${ }^{28,29,34,35}$ competitive protein-binding assays, ${ }^{24-27,37}$ an automated benchtop immunoanalyzer ${ }^{21}$ or a blood spot assay. ${ }^{22}$ These inconsistent methods might contribute to some of the variability in the study findings. This may be exacerbated by the fact that these studies were conducted on different continents and/or at different time points. Genetic factors might further have a role leading to more variation. In addition, there is very limited information on the food or nutrient intake by the study participants. It would be crucial to know, whether investigators and study participants used vitamin D-rich or -fortified products during hospitalization, rehabilitation or in daily life. In future, we need consistent threshold values for vitamin D deficiency and optimal vitamin D status as well as a consistent method to assess total serum $25[\mathrm{OH}]$ vitamin D concentration.

\section{CONCLUSION}

This literature review shows, that the occurrence of vitamin D deficiency among individuals with a SCI seems to be higher compared with that in able-bodied controls. In analogy to the able-bodied literature, a high body mass index, low physical activity, dark skin color, winter months and indoor sports are associated with vitamin D deficiency. In addition, parathyroid hormone, free and total testosterone concentration are negatively correlated with the vitamin $\mathrm{D}$ status in individuals with a SCI. Further supplementation studies are needed, to give accurate recommendations or guidelines to prevent vitamin $\mathrm{D}$ deficiency in individuals with an acute and chronic SCI. In the meantime, we recommend to check vitamin D status regularly and to supplement deficient individuals with a dose in the range of 1000-2000 IU daily. ${ }^{24}$ Furthermore, we recommend an active, healthy lifestyle with regular outdoor activities to prevent patients from a vitamin D deficiency.

\section{CONFLICT OF INTEREST}

The authors declare no conflict of interest.

1 Bischoff-Ferrari HA, Dawson-Hughes B, Willett WC, Staehelin HB, Bazemore MG, Zee RY et al. Effect of Vitamin D on falls: a meta-analysis. JAMA 2004; 291: 1999-2006.

2 Bruyere O, Cavalier E, Souberbielle JC, Bischoff-Ferrari HA, Beaudart C, Buckinx F et al. Effects of vitamin $\mathrm{D}$ in the elderly population: current status and perspectives. Arch Public Health 2014; 72: 32.

3 Carroll A, Onwuneme C, McKenna MJ, Mayne PD, Molloy EJ, Murphy NP. Vitamin D status in Irish children and adolescents: value of fortification and supplementation. Clin Pediatr (Phila) 2014; 53: 1345-1351.

4 Pludowski P, Karczmarewicz E, Bayer M, Carter G, Chlebna-Sokol D, Czech-Kowalska J et al. Practical guidelines for the supplementation of vitamin $\mathrm{D}$ and the treatment of deficits in Central Europe - recommended vitamin D intakes in the general population and groups at risk of vitamin D deficiency. Endokrynol Pol 2013; 64: 319-327.

5 Farrokhyar F, Tabasinejad R, Dao D, Peterson D, Ayeni OR, Hadioonzadeh R et al. Prevalence of vitamin $\mathrm{D}$ inadequacy in athletes: a systematic-review and meta-analysis. Sports Med 2015; 45: 365-378.

6 Reid IR. What diseases are causally linked to vitamin D deficiency? Arch Dis Child 2016; 101: 185-189.

7 Calder AD. Radiology of osteogenesis imperfecta, rickets and other bony fragility states. Endocr Dev 2015; 28: 56-71.

8 Tsugawa N. [Bone and nutrition. Vitamin D intake and bone]. Clin Calcium 2015; 25 : 973-981.

9 Szabo A. [Skeletal and extra-skeletal consequences of vitamin D deficiency]. Orv Hetil 2011; 152: 1312-1319.

10 Mandarino NR, Junior F, Salgado JV, Lages JS, Filho NS. Is vitamin D deficiency a new risk factor for cardiovascular disease? Open Cardiovasc Med J 2015; 9: 40-49.

11 Beveridge LA, Witham MD. Controversy in the link between vitamin D supplementation and hypertension. Expert Rev Cardiovasc Ther 2015; 13: 971-973.

12 Annweiler C, Rolland Y, Schott AM, Blain H, Vellas B, Herrmann FR et al. Higher vitamin $D$ dietary intake is associated with lower risk of Alzheimer's disease: a 7-year follow-up. J Gerontol A Biol Sci Med Sci 2012; 67: 1205-1211.

13 Wong G, Lim WH, Lewis J, Craig JC, Turner R, Zhu K et al. Vitamin D and cancer mortality in elderly women. BMC Cancer 2015; 15: 106.

14 Ceglia L, Harris SS. Vitamin D and its role in skeletal muscle. Calcif Tissue Int 2013; 92: 151-162.

15 Zittermann A. Vitamin D in preventive medicine: are we ignoring the evidence? Br J Nutr 2003; 89: 552-572.

16 Garland DE, Stewart CA, Adkins RH, Hu SS, Rosen C, Liotta FJ et al. Osteoporosis after spinal cord injury. J Orthop Res 1992; 10: 371-378. 
17 Biering-Sorensen F, Bohr HH, Schaadt OP. Longitudinal study of bone mineral content in the lumbar spine, the forearm and the lower extremities after spinal cord injury. Eur J Clin Invest 1990; 20: 330-335.

18 Holick MF. Optimal vitamin D status for the prevention and treatment of osteoporosis. Drugs Aging 2007; 24: 1017-1029.

19 Bartoszewska M, Kamboj M, Patel DR. Vitamin D, muscle function, and exercise performance. Pediatr Clin North Am 2010; 57: 849-861.

20 Holick MF. Vitamin D: A millenium perspective. J Cell Biochem 2003; 88 296-307.

21 Flueck JL, Hartmann K, Strupler M, Perret C. Vitamin D deficiency in Swiss elite wheelchair athletes. Spinal Cord 2016; 54: 991-995.

22 Pritchett K, Pritchett R, Ogan D, Bishop P, Broad E, LaCroix M. 25(OH)D Status of Elite Athletes with Spinal Cord Injury Relative to Lifestyle Factors. Nutrients 2016; 8: pii: E374.

23 Hummel K, Craven BC, Giangregorio L. Serum 25(OH)D, PTH and correlates of suboptimal 25(OH)D levels in persons with chronic spinal cord injury. Spinal Cord 2012; 50: 812-816.

24 Bauman WA, Emmons RR, Cirnigliaro CM, Kirshblum SC, Spungen AM. An effective oral vitamin D replacement therapy in persons with spinal cord injury. J Spinal Cord Med 2011; 34: 455-460.

25 Vaziri ND, Pandian MR, Segal JL, Winer RL, Eltorai I, Brunnemann S. Vitamin D, parathormone, and calcitonin profiles in persons with long-standing spinal cord injury. Arch Phys Med Rehabil 1994; 75: 766-769.

26 Zhou XJ, Vaziri ND, Segal JL, Winer RL, Eltorai I, Brunnemann SR. Effects of chronic spinal cord injury and pressure ulcer on $25(\mathrm{OH})$-vitamin D levels. J Am Paraplegia Soc 1993; 16: 9-13.

27 Bauman WA, Zhong YG, Schwartz E. Vitamin D deficiency in veterans with chronic spinal cord injury. Metabolism 1995; 44: 1612-1616.

28 Pedrera JD, Manas P, Gomez MA, Canal ML, Lavado JM, Hernandez ER et al. Ultrasound bone mass in paraplegic patients. Spinal Cord 2002; 40: 83-87.

29 Javidan AN, Sabour H, Latifi S, Vafa M, Shidfar F, Khazaeipour Z et al. Calcium and vitamin D plasma concentration and nutritional intake status in patients with chronic spinal cord injury: a referral center report. J Res Med Sci 2014; 19: 881-884.

30 Barbonetti A, Sperandio A, Micillo A, D'Andrea S, Pacca F, Felzani G et al. Independent association of aitamin D with physical function in people with chronic spinal cord injury. Arch Phys Med Rehabil 2016; 97: 726-732.

31 Barbonetti A, Vassallo MR, Felzani G, Francavilla S, Francavilla F. Association between 25(OH)-vitamin $D$ and testosterone levels: evidence from men with chronic spinal cord injury. J Spinal Cord Med 2015; 39: 246-252.

32 Bauman WA, Morrison NG, Spungen AM. Vitamin D replacement therapy in persons with spinal cord injury. J Spinal Cord Med 2005; 28: 203-207.

33 Benlidayi IC, Basaran S, Seydaoglu G, Guzel R. Vitamin D profile of patients with spinal cord injury and post-stroke hemiplegia: all in the same boat. J Back Musculoskelet Rehabil (e-pub ahead of print 6 July 2015; doi:10.3233/BMR-150615).

34 Oleson CV, Patel PH, Wuermser LA. Influence of season, ethnicity, and chronicity on vitamin D deficiency in traumatic spinal cord injury. J Spinal Cord Med 2010; 33: 202-213.

35 Nemunaitis GA, Mejia M, Nagy JA, Johnson T, Chae J, Roach MJ. A descriptive study on vitamin $D$ levels in individuals with spinal cord injury in an acute inpatient rehabilitation setting. PM R 2010; 2: 202-208 quiz 228.
36 Karapolat I, Karapolat HU, Kirazli Y, Capaci K, Akkoc Y, Kumanlioglu K. Longitudinal study of bone loss in chronic spinal cord injury patients. J Phys Ther Sci 2015; 27: 1429-1433.

37 Mechanick JI, Pomerantz F, Flanagan S, Stein A, Gordon WA, Ragnarsson KT. Parathyroid hormone suppression in spinal cord injury patients is associated with the degree of neurologic impairment and not the level of injury. Arch Phys Med Rehabil 1997; 78: 692-696.

38 Ritter CS, Brown AJ. Direct suppression of Pth gene expression by the vitamin D prohormones doxercalciferol and calcidiol requires the vitamin $D$ receptor. $\mathrm{J}$ Mol Endocrinol 2011; 46: 63-66.

39 Moslehi N, Shab-Bidar S, Mirmiran P, Hosseinpanah F, Azizi F. Determinants of parathyroid hormone response to vitamin $D$ supplementation: a systematic review and meta-analysis of randomised controlled trials. Br J Nutr 2015; 114: 1360-1374.

40 Deckers MM, de Jongh RT, Lips PT, Penninx BW, Milaneschi Y, Smit JH et al. Prevalence of vitamin D deficiency and consequences for PTH reference values. Clin Chim Acta 2013; 426: 41-45.

41 Jiang SD, Dai LY, Jiang LS. Osteoporosis after spinal cord injury. Osteoporos Int 2006; 17: $180-192$.

42 Anagnostis P, Karras S, Goulis DG. Vitamin D in human reproduction: a narrative review. Int J Clin Pract 2013; 67: 225-235.

43 Blomberg Jensen M. Vitamin D and male reproduction. Nat Rev Endocrinol 2014; 10: 175-186.

44 Kirmani S, Atkinson EJ, Melton LJ 3rd, Riggs BL, Amin S, Khosla S. Relationship of testosterone and osteocalcin levels during growth. J Bone Miner Res 2011; 26: 2212-2216.

45 Heijboer AC, Oosterwerff M, Schroten NF, Eekhoff EM, Chel VG, de Boer RA et al. Vitamin $D$ supplementation and testosterone concentrations in male human subjects. Clin Endocrinol (Oxf) 2015; 83: 105-110.

46 Pilz S, Frisch S, Koertke H, Kuhn J, Dreier J, Obermayer-Pietsch B et al. Effect of vitamin D supplementation on testosterone levels in men. Horm Metab Res 2011; 43: 223-225.

47 Kalava UR, Cha SS, Takahashi PY. Association between vitamin D and pressure ulcers in older ambulatory adults: results of a matched case-control study. Clin Interv Aging 2011: 6: 213-219.

48 Libon F, Cavalier E, Nikkels AF. Skin color is relevant to vitamin D synthesis. Dermatology 2013; 227: 250-254.

49 Wortsman J, Matsuoka LY, Chen TC, Lu Z, Holick MF. Decreased bioavailability of vitamin D in obesity. Am J Clin Nutr 2000; 72: 690-693.

50 Close GL, Russell J, Cobley JN, Owens DJ, Wilson G, Gregson W et al. Assessment of vitamin $\mathrm{D}$ concentration in non-supplemented professional athletes and healthy adults during the winter months in the UK: implications for skeletal muscle function. J Sports Sci 2013; 31: 344-353

51 Halliday TM, Peterson NJ, Thomas JJ, Kleppinger K, Hollis BW, Larson-Meyer DE. Vitamin D status relative to diet, lifestyle, injury, and illness in college athletes. Med Sci Sports Exerc 2011; 43: 335-343.

52 Willis KS, Smith DT, Broughton KS, Larson-Meyer DE. Vitamin D status and biomarkers of inflammation in runners. Open Access J Sports Med 2012; 3: 35-42.

53 Storlie DM, Pritchett K, Pritchett R, Cashman L. 12-Week vitamin D supplementation trial does not significantly influence seasonal $25(\mathrm{OH})$ D status in male collegiate athletes. Int J Health Nutr 2011; 2: 8-13.

54 Constantini NW, Arieli R, Chodick G, Dubnov-Raz G. High prevalence of vitamin D insufficiency in athletes and dancers. Clin J Sport Med 2010; 20: 368-371. 